This article has been scanned by iThenticat No plagiarism detected

Volume 3, Issue 4, August 2021

p. 286-293

\title{
AUTHENTICITY AND ORIGINALITY IN THE FIRE OF MOHAMMED DIB
}

http://dx.doi.org/10.47832/2757-5403.4-3.25

\begin{abstract}
:
French-speaking Algerian writers find themselves forced to situate themselves in relation to French literature and their representation of Algerian reality. They are writers who have been specific in their distinction from the literature of the West because they have allowed the reader to discover the national heritage as well as the culture of their country.

In order to highlight the richness and the multiplicity of the romantic forms of Africa, our major concern will be center on the sociocritical study of the novel of Dib "The Fire" with the aim of highlighting the social anchoring of the text and extract traces of Algerian culture.

This cultural richness is manifested through the anchoring of Islam, the use of expressions referring to the culture of Algerians. Originality is also reflected in the picture he paints of his society in his daily life.

The structure of Dib's work reveals close relations with Algerian culture, on the one hand, on the other hand, this orientation of the writing gives it an aesthetic particularity, The return to the sources and the valuation of its identity gives to the Dibien text its authenticity and originality.
\end{abstract}

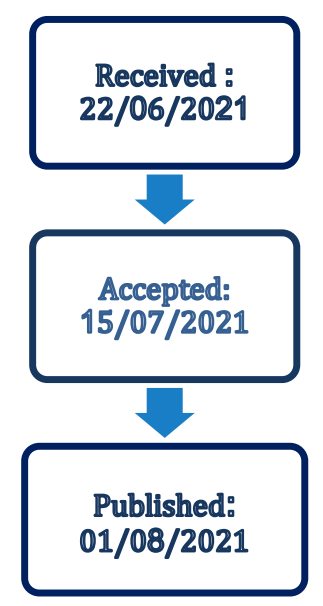

Key words: Writing, Literature, Authenticity, Originality, Culture.

\footnotetext{
${ }^{1}$ Dr. , Kasdi Merbah Ouargla University, Algeria, hac.louiza@gmail.com, https://orcid.org/0000-0002-1602$\underline{9612}$
}

Copyright (C) Published by IJHER Journal, www.ijherjournal.com

Rimar Academy, Fatih, Istanbul, 34093 Turkey

All rights reserved 


\title{
AUTHENTICITÉ ET ORIGINALITÉ DANS L'INCENDIE DE MOHAMMED DIB
}

\section{Hachani Louiza}

\begin{abstract}
Résumé
Les écrivains algériens d'expression française se trouvent contraints de se situer par rapport à la littérature française et à leurs représentation de la réalité algérienne. Ce sont des écrivains qui ont été spécifiques par leur distinction de la littérature de l'Occident car ils ont permis au lecteur de découvrir le patrimoine national ainsi que la culture de leur pays.

Afin de mettre en évidence la richesse et la multiplicité des formes romanesques d'Afrique, notre préoccupation majeure sera center sur l'étude sociocritique du roman de Dib "L'Incendie" dans le but de mettre en relief l'ancrage social du texte et extraire les traces de la culture algérienne.

Cette richesse culturelle est manifestée à travers l'ancrage de l'Islam, l'emploi des expressions faisant référence à la culture des algériens. L'originalité se traduit aussi à travers le tableau qu'il peint de sa société dans son quotidien.

La structure de l'œuvre de Dib révèle des relations étroites avec la culture algérienne, d'une part, d'autre part, cette orientation de l'écriture lui donne une particularité esthétique, Le retour aux sources et la valorisation de son identité donne au texte dibien son authenticité et son originalité.

Mots-clés: Écriture, Littérature, Authenticité-Originalité, Culture.
\end{abstract}


L'aire culturelle et linguistique du Maghreb s'est constituée au fil des siècles autour des populations berbères autochtones qui étaient soumises à plusieurs grandes vagues d'occupation.

Dans cet archipel particulier, la littérature a subi en effet les influences successives des cultures punique et juive, grecque et latine, vandale et byzantine, arabe puis turque et française, avant que ne se constituent les nations modernes indépendantes que nous connaissons.

L'adhésion à l'Islam, à partir du VIIIe siècle Après. J.C s'est faite de façon progressive et continue, au point de devenir, à l'heure actuelle, l'un des ciments de la culture maghrébine. Celle-ci a su conserver une identité propre, distincte de celle de l'Europe comme de celle du monde arabe, au carrefour de l'Afrique, de l'Orient et de l'Occident.

L'œuvre dibienne a essentiellement un goût de l'expérience et de l'authenticité. Elle nous fait introduire dans notre monde, avec ses complexités et ses déchirements.

C'est aussi un "acte de foi " comme le dit l'écrivain lui-même, une écriture où cherche obscurément sa force une parole intérieure fuyante et vivante. Nous voulons dire par l'expression le pouvoir de l'écriture, les moyens pour l'écriture de manifester, dans l'unité et l'ombre de ses signes. Cet ancrage dans la culture d'origine lui donne l'existence pour soimême en créant comme sens. Ce qui est visé par cette mise en relief de la culture confère à l'œuvre son authenticité.

Notre étude vise à démonter l'aspect original et authentique de l'œuvre dibienne, précisément dans son deuxième volet de la trilogie 'L'Incendie" afin de voir à quoi l'auteur se réfère-t-il ? Et sur quoi il s'appuie et d'où puise-t-il cette particularité des écrits d'expression française ?

Au Maghreb, et particulièrement en Algérie, toute l'organisation sociale s'articule autour de la cellule familiale, c'est-à-dire : l'ensemble de toutes les personnes vivantes ou défuntes qui connaissent un ancêtre commun le microcosme, la cellule première que produisent par dilatation tous les cercles concentriques qui forment les divers étages de la société : village, tribu, royaume, empire, etc.

Le retour aux sources et la revalorisation de la civilisation ne sont toutefois pas une fin en soi, et Dib s'efforce de déterminer le rôle de l'homme de culture dans la société contemporaine.

D'une part, Jacques Chevrier estime que "les écrivains et les artistes doivent jouer un rôle de premier plan dans la lutte pour la décolonisation, l'administration de la cité n'est qu'un aspect de la culture" (Chevrier, 1974). D'autre part, il pense que face à l'Occident, l'Afrique, peut et doit jouer un rôle important dans la construction du monde de demain dans la mesure où

se doter d'un passé, c'est en effet se doter d'un nom, donc retrouver son identité mais assujettir l'Occident, la nécessité pour les peuples de sauvegarder leur personnalité propre, récupérer et d'enrichir le patrimoine culturel et de promouvoir dans tous les domaines leur authenticité gravement aliénée par les colonialistes. (Chevrier, 1974)

Pendant la domination coloniale, les cultures africaines, notamment algérienne et leurs langues d'expression ont subi le sort réservé aux cultures de l'homme primitif : si elles n'étaient pas ignorées, elles étaient niées. Comme le note Frantz Fanon : "tout peuple colonisé c'est-à-dire : tout peuple au sein duquel a pris naissance un complexe d'infériorité $\mathrm{du}$ fait de la mise au tombeau de l'originalité culturelle locale se situe vis-à-vis de la culture métropolitaine" (Fanon, 1952).

Toutefois, nous avons remarqué que nous assistons actuellement à un mouvement de recul des intellectuels africains et notamment maghrébins vis-à-vis du problème fondamental de la langue d'origine car au moment où ils prônent le retour à la tradition, ils continuent à s'exprimer en français.

A partir de l'étude faite sur l'œuvre de L'Incendie, Nous avons pu faire un relevé précis des traces faisant référence à l'originalité de l'œuvre à l'exemple de certains éléments que nous évoquons ci-dessous:

- Les Croyances

Les croyances font partie du quotidien des Maghrébins. Nous avons remarqué leur emploi dans notre corpus lorsque l'auteur évoque le surnaturel et la superstition.

- Le surnaturel 
Le monde surnaturel intervient dans le roman maghrébin. Il fait partie de la croyance. Pour les personnages de Dib, les deux mondes entrent en relation, ce qui favorise l'attente chez le lecteur, donc le surnaturel surgit de façon organisée. Cela est démontré dans cette citation : "Inscrits dans les structures mentales du lecteur, ce qui lui donne sa permanence et sa réalité, le surnaturel acquiert donc dans le roman africain un statut immanent à l'intrigue romanesque" (Echenim, 1981). Le surnaturel est manifesté par les légendes racontées dans les romans. Dans celui de Dib, nous trouvons l'histoire légendaire de Comandar:

Un immense cheval bondit vers le ciel et hennit. La vieille terre se tut. Et le feu blanc s'éteignit.

(...) Comandar lui raconta ce que les fellahs avaient observé au cours d'une nuit:

La lune d'été écumait au-dessus des abîmes noirs qui s'ouvraient entre les monts. Ce n'était plus la nuit. L'air, la terre, resplendissaient. On pouvait distinguer chaque touffe d'herbe, chaque motte. L'air, la terre, et la nuit respiraient d'un souffle imperceptible. Soudain un bruit de sabots frappant le sol se répercuta à travers la campagne. Tous les fellahs se dressèrent sur leur séant. Le bruit se rapprocha encore : ce fut comme un tonnerre roulant d'une extrémité à l'autre de la contrée. Puis aucun fellah n'avait sommeil. Certains qui s'étaient installés devant leurs gourbis virent sous les murailles de Mansourah un cheval blanc, sans selle, sans rênes, sans cavalier, sans harnais, la crinière secouée par une course folle. Un cheval sans rênes ni selle dont la blancheur éblouit. Et la bête prodigieuse s'enfonça dans les ténèbres(...) Et depuis, ceux qui cherchent une issue à leur sort, ceux qui, en hésitant, cherchent leur terre, qui veulent s'affranchir leur sol, se réveillent chaque nuit et tendent l'oreille. La folie de la liberté leur est montée au cerveau. Qui te délivrera, Algérie ? Ton peuple marche sur les routes et te cherche. (Dib M. , L'Incendie, 1954)

À partir de cette légende de Comandar, nous pouvons avoir une idée sur la vie à Bni Boublen. Le cheval qui galope, c'est cette liberté dont songent les fellahs. Ce cheval fait appel à la résistance.

L'auteur emploie une expression au prologue qui lance le même message signifiant le surnaturel :

Les fantômes de Abdelkader et de ses hommes rôdent sur ces terres insatisfaites" (Dib M. , L'Incendie, 1954).

- De la superstition

Il s'agit d'une

forme élémentaire et particulière des sentiments religieux consistant dans la croyance à des présages tirés d'événements matériels fortuits (salière renversée, nombre treize, etc.).

Préjugé et pratique des gens superstitieux. Attachement exclusif, exagéré ou non justifié, à quelque chose. (www.larousse.fr, s.d.)

Dans "L'Incendie ", plusieurs expressions relevant des croyances algériennes, se lisent dans : "Tu sais ce qu'on dit ? expliqua Mama. Ceux qui racontent des histoires en plein jour auront des enfants teigneux." (Dib M. , L'Incendie, 1954).

- Le chant

Il est à noter que "chanson" est un terme qui

a connu les acceptions les plus diverses. Il apparaît pour la première fois au XIème siècle, dans l'appellation chanson de geste (qui est un poème épique - voir épopée). (...) La chanson qui intéresse la littérature orale est la chanson dite folklorique. Cette chanson prise en considération très tardivement fera l'objet de collectes (décret du 13 septembre 1852). Cette collecte aujourd'hui disponible pour beaucoup de régions ne semble pas témoigner de chansons antérieures au XVème siècle (hormis les chansons des troubadours transmises par les parchemins). Au XXème siècle, la disparition de l'analphabétisme prive la chanson de son rôle social d'informateur 
et de mobilisateur. Dans le monde, la chanson peut avoir de nombreuses fonctions : arme permettant de ridiculiser l'adversaire chez les Inuits, support du récit chez les griots, déclaration d'amours chez les Touaregs (euroconte.org, 2017)

Slimane Meskine, Comandar de Khadra, durant une conversation avec Ba Dedouche, essayant d'éviter les questions de celui-ci, il propose de chanter une petite chanson.

Slimane chante un chant de douleur et de désespoir, dans :

Oh, Mama-la-la maritorne

Pousse une tendre chanson,

La marmite bout

Et les escargots sont bons ! (Dib M. , 1954)

Slimane reprit le chant et cette fois, sa voix s'amplifia :

Nous guettons le jour,

Du fond des yeux nous gardons

Sur les montagnes

Se délier la nuit incombustible ;

-des feux

Allumés chaque soir

Aux foyers de nos demeures,

Des feux de joie parmi les monts

Gagnent les frontières du monde (Dib M. , L'Incendie, 1954)

Ce chant explique la situation dans laquelle se trouve le village, l'inertie et l'oisiveté. Slimane veut que la vie reprenne. Mais le chant crée une certaine peur chez Ba Dedouche qui, pour lui, un drame va survenir.

Le recours au chant, loin d'être ici une manifestation d'euphorie, s'entend plutôt comme l'expression d'un profond désespoir né d'une situation de blocage, d'inertie totale, sans ouverture sur le futur. Le devoir de ceux qui s'ennuient est de sortir de leur torpeur, de se secouer pour que la vie reprenne. (Berrarhi, L'Incendie, étude critique, 2015)

Les sentiments de $\mathrm{Ba}$ Dedouche se confirment en entendant le chant du vieux Comandar dans le fond de la campagne

O...mon cheval... qu'a-tu?

O...mon cheval... (Dib M. , 1954)

C'était des lamentations. Pour Comandar le cheval est associé à la liberté, il est l'espoir de ce peuple.

Le chant de Comandar "come une lamentation", sur l'autre versant, parvient en réponse à leurs oreilles. Le chant couvre la distance et tisse le lien inattendu. Il témoigne d'une semblable préoccupation. Il est signe de solidarité (Berrarhi, L'Incendie, étude critique, 2015).

Comandar crie la parole de l'espoir en s'opposant au chant de Slimane :

Il titubait comme sous l'empire du vin qui terrasse l'ivrogne. Son visage tourné tantôt vers l'ombre diffuse d'une nuit claire, tantôt vers l'obscurité impénétrable des collines, prenait tour à tour une expression crispée, sombre, paisible, gaie (Dib M. , L'Incendie, 1954).

Lorsque l'incendie est allumé, le même chant de l'espoir est récité par Slimane Meskine et Azouz. Celui-ci a perdu sa femme dans l'incendie.

À la fin du chapitre IV de L'Incendie, le chant d'une femme pour son fils, celui de Khadra qui témoigne de la tendresse qu'elle éprouve pour son fils, elle lui chantonne d'une voix étouffée tandis qu'elle le porte sur le dos.

Dans mon jardin

J'ai semé des graines d'anis

Attirés par leur douceur

Les oiseaux sont venus;

Je les ai chassés

Avec des paraboles (Dib M. , 1954).

- Les devinettes 
Selon le Dictionnaire Le Larousse en ligne, une devinette renvoie à " ce que l'on donne à deviner; question le plus souvent plaisante, dont on demande à quelqu'un, par jeu, de deviner la réponse ; énigme» (www.larousse.fr, s.d.)

Dans "L'Incendie", nous avons pu repérer deux devinettes dites par Mama pour Omar et Zhor :

* -Jaune et fané, entouré de langes : devine-moi ce que c'est, ou va-t'en de mes côtés $(. .$.

-Le mais ! Le mais ! S'écria-t-1, avant qu'elle eut fini.

* -Une maison de fer j'ai, par des nègres hantés : devine-moi ce que c'est, ou tu auras cents coups de mon fouet $(. .$.

-La pastèque, idiot ! révéla Zhor (Dib M. , 1954).

- Les proverbes

Ils renvoient à des formules langagières constituant

le genre le plus paradoxal de la littérature orale. L'un des plus anciens, sans doute, mais aussi celui qui a le mieux résisté à l'érosion du temps. Difficile à cerner [...]. À la fois évident et énigmatique, c'est une œuvre d'art en miniature qui fait les délices du peuple et l'admiration des créateurs. [...]. Sa concision fait de lui le genre le plus souvent collecté, illustré, expliqué, développé et aussi, suivant les époques, méprisé et combattu. (Soriano, 2017)

L'auteur utilise quelques proverbes que nous regroupons dans le tableau ci-dessous :

\begin{tabular}{|l|l|}
\hline Proverbe & Signification \\
\hline L'Incendie \\
$\begin{array}{l}\text { "Je couperai le miel dans ta bouche" (Dib } \\
\text { M. 1954) }\end{array}$ & $\begin{array}{l}\text { On le dit par courtoisie, pour interrompre } \\
\text { quelqu'un qui parle. }\end{array}$ \\
\hline $\begin{array}{l}\text { "Attendez-vous à ce que le sel fleurisse ! } \\
\text { Plaisantèrent les deux journaliers" (Dib } \\
\text { M. , 1954) }\end{array}$ & $\begin{array}{l}\text { Un proverbe équivalent à l'expression "en } \\
\text { attendant Godot". }\end{array}$ \\
\hline $\begin{array}{l}\text { "Au revoir Slimane dit-il, tu n'as rien } \\
\text { senti ? Depuis un moment une mauvaise } \\
\text { odeur m'empêche de respirer." (Dib M. , } \\
\text { 1954) }\end{array}$ & $\begin{array}{l}\text { C'était Ali Berabah qui avait dit cette } \\
\text { pas le bienvenu. }\end{array}$ \\
\hline $\begin{array}{l}\text { "Chaque fois, ils m'ont reçue sur la } \\
\text { pupille de leurs yeux." (Dib M. , 1954) }\end{array}$ & Elle était bien accueillie. \\
\hline $\begin{array}{l}\text { "Nous nous ne sommes pas venues pour } \\
\text { nous asseoir. Nous sommes venues d'un } \\
\text { seul pied " (Dib M. , 1954) }\end{array}$ & Elles sont pressées. \\
\hline
\end{tabular}

Tableau 1 : Les proverbes contenus dans les romans de L'Incendie

Certaines expressions issues du parler arabe ne sont pas des proverbes mais des expressions en usage. L'auteur les traduit littéralement et les reprend. Nous remarquons aussi quelques habitudes de la société algérienne dans : "AAïni, comme à l'accoutumée, avait serré cette monnaie dans un nœud de son vaste mouchoir de coton" (Dib M. , 1954).

- Les tenues vestimentaires symboles de culture

Nous jugeons utile d'évoquer cette question d'habits du moment qu'elle est représentative de la culture. Elle fait référence à l'apparence des habitants du pays.

L'auteur nous informe sur les tenues vestimentaires de ses personnages, c'est un détail de l'observation de l'auteur, qui n'est pas fortuit. C'est un ancrage total, la tradition du Maghreb et qui touche non seulement la parole des personnages mais aussi celle des habitudes et d'autres pratiques sociales. Nous relevons les passages suivants pour plus d'illustration.

- Les femmes algériennes se couvrent avec des Haïk, une référence appartenant au patrimoine algérien, il est le symbole de la féminité. Tel le montre l'extrait : "De haute carrure, drapées dans la flambante blancheur des jaiks (haik)" (Dib M. , 1954)

Les femmes cachent leurs cheveux, une coutume algérienne car il n'existe pas de femme qui montre ses cheveux. Ce que nous lisons dans: "Quelques-unes 
revenaient déjà ; vêtues de cotonnades, toutes avaient des corps rudes. Le vaste mouchoir de couleur qui leur entourait la tête empêchait de voir leurs cheveux" (Dib M. , 1954).

- L'ancrage de l'Islam dans les deux romans

Les littératures maghrébine d'expression française imprégnée de la religion de l'Islam, nous nous sommes aussi intéressées aux expressions relevant de notre religion, marquant l'appartenance à la l'Islam, et montrant que le peuple est issu d'une culture arabomusulmane. C'est ce qu'illustrent les expressions suivantes :

\begin{tabular}{|c|c|}
\hline Expression & Signification \\
\hline \multicolumn{2}{|l|}{ L'Incendie } \\
\hline Salam & Salutation des musulmans. \\
\hline Salam et bénédiction! (Dib M. , 1954) & Pour répondre à une salutation \\
\hline $\begin{array}{l}\text { Allah vous vienne en aide (Dib M. , } \\
\text { 1954) }\end{array}$ & $\begin{array}{l}\text { Dieu vous aide est une expression dite } \\
\text { lorsque les hommes sont en besogne. }\end{array}$ \\
\hline $\begin{array}{l}\text { Bénis soient tes père et mère (Dib M. } \\
\text { 1954) }\end{array}$ & Pour remercier quelqu'un. \\
\hline L'heure du dhor (Dib M. , 1954) & $\begin{array}{l}\text { en référence à l'heure de la prière du } \\
\text { début de l'après-midi. }\end{array}$ \\
\hline $\begin{array}{l}\text { Il bredouillait et toussait (Dib M. } \\
\text { 1954) : Ehm ! Ehm ! }\end{array}$ & $\begin{array}{l}\text { Ces excès de toux n'en imposaient à } \\
\text { personne. Les fellahs lui tournèrent le } \\
\text { dos : Kara Ali toussait pour imposait le } \\
\text { respect d'un homme de haute } \\
\text { considération. }\end{array}$ \\
\hline $\begin{array}{l}\text { Bénis soient tes aïeux ! (Dib M. , } \\
\text { L'Incendie, 1954) }\end{array}$ & $\begin{array}{l}\text { Une expression utilisée } \\
\text { encourager Hamid Saraj }\end{array}$ \\
\hline $\begin{array}{l}\text { Pourtant, il est dit : agissez comme si } \\
\text { votre mort était pour demain, mais } \\
\text { accomplissez vos devoirs comme si } \\
\text { vous deviez vivre l'éternité. Soit dit } \\
\text { sans vous vexer (Dib M. , L'Incendie, } \\
\text { 1954) }\end{array}$ & $\begin{array}{l}\text { Un Hadith de Ali Que la paix soit sur } \\
\text { lui. }\end{array}$ \\
\hline $\begin{array}{l}\text { Mais, vous ne figurez pas ce que c'est } \\
\text { que la douane. On dirait le sirath est } \\
\text { plus effilé qu'une épée et plus fin qu'un } \\
\text { cheveu (Dib M. , L'Incendie, 1954) }\end{array}$ & $\begin{array}{l}\text { Aini a comparé le passage par la } \\
\text { douane au trajet-épreuve que doivent } \\
\text { suivre les humains le jour du jugement } \\
\text { dernier. }\end{array}$ \\
\hline $\begin{array}{l}\text { Les anges m'en tiendront compte, } \\
\text { j'espère, dans le grand livre des bonnes } \\
\text { actions (Dib M. , L'Incendie, 1954) }\end{array}$ & Une prière. \\
\hline $\begin{array}{l}\text { Aïni, ma petite sœur, maudis Satan } \\
\text { (Dib M. , L'Incendie, 1954) }\end{array}$ & Pour qu'Aïni soit raisonnable \\
\hline $\begin{array}{l}\text { C'est Iblis qui vous mène paître ces } \\
\text { vaches (Dib M. , L'Incendie, 1954) }\end{array}$ & $\begin{array}{l}\text { Iblis c'est le nom de Satan dans le } \\
\text { Coran. }\end{array}$ \\
\hline
\end{tabular}

Tableau 3 : Expressions religieuses contenues dans les roman-corpus

À partir de ce tableau, nous constatons que l'auteur réserve une place primordiale à la religion, elle se manifeste dans certains comportements des personnages.

Certaines expressions sont même utilisées dans la langue d'origine de la religion : l'arabe.

\section{Conclusion}

$\mathrm{Au}$ terme de notre recherche, nous dirons que nous avons pu montrer comment se manifeste l'originalité et l'authenticité de l'œuvre de Dib. L'auteur, par l'intermédiaire de son écrit respectif, non seulement son engagement manifesté tout au long de la thématique romanesque, mais aussi dans l'esthétique de l'écriture maghrébine combinant la lutte contre le colon et la question de l'identité et de la culture de son pays colonisé : un engagement et une création.

Notre corpus traite de la question coloniale et identitaire. Mais l'identité ne se réduit pas à l'espace, elle se définit comme un univers mental rassemblant des croyances et des 
traditions propres à l'Afrique. L'anticolonialisme chez l'écrivain se focalise sur la dénonciation de l'idéologique de l'acculturation des indigènes. L'auteur peint le réalisme de la vie sous la colonisation française et partage avec le lecteur la culture du peuple.

Compte tenu que la colonisation avait pour objectif de réprimer des cultures, d'assimiler les indigènes et d'étouffer leurs cultures propres, la littérature orale demeure l'expression de l'identité culturelle, la sauvegarde de l'histoire d'une communauté et la mémoire du peuple. Les matériaux oraux (mythes, chants, devinettes, contes, légendes, proverbes) sont transmis d'une génération à une autre pour incarner les années passées des sociétés. Les écrits populaires se font dans un style spontané où l'auteur trouve lieu d'exprimer ses sentiments les plus profonds.

Ils puisent d'un bain culturel purement propre à leur pays, ce que nous avons remarqué à travers l'emploi excessif des mots et des expressions traduits de leurs langues maternelles. Ce sont des œuvres de création unique propre à nos auteurs d'expression française.

Les auteurs indigènes africains s'approprient la langue du colon pour donner naissance à cette "belle " création : l'écriture créative traçant l'identité des peuples colonisés. Ainsi, les rapports qu'entretiennent les lecteurs avec le texte sont multiples.

Notre objectif premier était de montrer l'importance de la référence culturelle dans la mise en relief de l'originalité et l'authenticité dans l'ouvre dibienne. Ce que nous avons atteint en affirmant qu'elle est le point de départ de toute écriture, élément que nous avons illustré à travers les traces intertextuelles dans le roman-corpus ; miroir de la pensée de l'écrivain.

La langue utilisée sert de moyen pour garder l'originalité des cultures et des traditions de l'Afrique. Et c'est là où nous avons rencontré des difficultés pour effectuer l'analyse narrative des

En effet, l'analyse menée a permis de comparer, dans l'ensemble des hypothèses, formulées au départ et, a donné un éclairage nouveau sur la manière dont sont utilisés ces termes et expressions de la langue maternelle.

Pour aller au-delà du thème abordé, d'autres interrogations pourraient être évoquées :

$>$ Une étude sur le discours dans l'œuvre de Dib serait-elle une sorte de renouvellement du discours, une métamorphose et un changement de la forme ?

$>$ Dans cette Afrique accablée de tous les maux, il serait nécessaire de s'intéresser au thème de la misère qui s'annonce comme perspective de recherche ou encore celui de la violence dans les deux romans étudiés.

On pourrait enfin s'interroger sur le devenir du patrimoine algérien dans une tentative de le sauvegarder, tout en se demandant : Le livre garantira-t-il l'authenticité de cet héritage culturel?

\section{Bibliographie}

(2017, août 30). Récupéré sur euroconte.org: http://www.euroconte.org Berrarhi, A. (2015). L'Incendie, étude critique. Paris: Honoré Champion.

Chevrier, J. (1974). Littérature nègre. Paris: Armand Colin.

Dib, M. (1954). L'Incendie. Paris: Seuil.

Echenim, K. (1981, nov-déc). De l'oralité dans le roman africai,. Peuples noires, peuples africains(24), p. 128.

Fanon, F. (1952). Peau noire, masques Blancs. Paris: Seuil collection Esprit.

Soriano, M. (2017, aout 30). Proverbes. Récupéré sur Encyclopédie Universalis: http:/ /www.universais.fr/encycopedie/proverbes /

www.larousse.fr. (s.d.). Récupéré sur larousse: http://www.larousse.fr 